\title{
PERFIL EPIDEMIOLÓGICO DAS INTERNAÇÕES, GASTOS E MORTALIDADE INTRA-HOSPITALAR, POR SEQUELAS DA TUBERCULOSE, NO BRASIL
}

\author{
EPIDEMIOLOGICAL PROFILE OF HOSPITALIZATIONS, EXPENSES AND \\ INTRAHOSPITAL MORTALITY, BY SEQUELS OF TUBERCULOSIS, IN \\ BRAZIL
}

Anna Maria Andrade Barbosa*, Bárbara de Oliveira Arantes, Yuri Borges Bitu de Freitas, Natan Augusto de Almeida Santana, Antonio Márcio Teodoro Cordeiro Silva.

Pontifícia Universidade Católica de Goiás, Goiânia, GO, Brasil.

*annamandrade@icloud.com

\section{RESUMO}

As formas graves da tuberculose (TB), TB multirresistente (TB-MDR) e TB extensivamente resistente a medicamentos (TB-XDR), têm tratamento longo, difícil, de alto custo e está associado às sequelas pós-infecciosas crônicas e perda de função orgânica. As sequelas da TB, normalmente, causam comprometimento dos pulmões, morbimortalidade e reduzem a qualidade de vida, principalmente de adultos jovens. Assim, a cura bacteriológica da TB pode marcar o início de uma doença respiratória crônica e infecções recorrentes. Tendo em vista esse panorama tem-se por objetivo descrever o perfil epidemiológico das internações por sequelas da tuberculose, no Brasil, considerando despesas e permanência hospitalares, região do país, faixa etária, sexo e óbito por meio de um estudo epidemiológico, do perfil das internações hospitalares, por sequelas da tuberculose, no período de 2010 a 2019, no Brasil, com dados extraídos do Sistema de Informações Hospitalares do SUS (SIHSUS), disponibilizados pelo DATASUS. Sob a luz da análise de dados em relação à região, foi observado, no Nordeste, o maior valor total de gastos $(R \$$ 6.881.786,51), por serviços hospitalares, em razão de sequelas de tuberculose, e em cada um de todos os anos avaliados. O maior valor foi gasto, no ano de 2015 (R\$1.120.344,15), contabilizando 51,3\% de todo o gasto do país. A região Norte apresentou situação contrária e, inclusive, em 2019, mostrou gasto de, apenas, $R \$ 166,95$. O maior valor total $(R \$ 2.182 .039,82)$, ocorreu em 2015. $A$ faixa etária mais afetada, em todos os anos, foi a de indivíduos com 50 a 59 anos de idade, e a menos foi a de 20 a 29 anos. Verificou-se diminuição razoável na morbidade hospitalar na faixa etária de 20 a 29 anos, quando comparados os anos anteriores e atuais, e diminuição progressiva, na faixa etária de 60 a 69 anos. A morbidade hospitalar e a mortalidade, por sequelas de tuberculose, foram maiores no sexo masculino, em todos os anos avaliado. A mortalidade feminina não sofreu alteração importante, durante os anos, mas a masculina apresenta diminuição, desde 2016. A mortalidade, em razão dessas sequelas, apresentou diminuição progressiva e foi, predominante, na região Sudeste $(n=30)$, seguida pelas regiões: Nordeste $(n=28)$ e Sul $(n=27)$. A região Norte teve menor mortalidade total $(n=3)$. No que concerne às internações por sequelas, a 
região Norte apresentou o menor número total $(n=57)$ e Nordeste, o maior ( $n=1.474)$, seguida pelo Sudeste ( $n=1.112)$. Logo, observou-se que os maiores valores gastos, por serviços hospitalares, em razão das sequelas por TB, durante todo o período analisado, foram na região Nordeste. Contudo, houve redução progressiva no número de internações, desde 2015, evidenciando que, desde então, a gestão em saúde passou a dar mais enfoque a esse setor, implementando projetos eficientes.

Palavras-chave: Doenças infecciosas. Epidemiologia. Mycobacterium. Sequelas. Tuberculose. 